\title{
Evaluation of Gastric Lesions Based on Helicobacter pylori and Helicobacter-Like Organisms (HLOs) in Cats; A Histopathological and Bacteriological Study
}

\author{
Farhang Sasani ${ }^{1, *}$; Javad Javanbakht ${ }^{1}$; Farrokh Reza Kabir ${ }^{2}$; Mehdi Agha Mohammad \\ Hassan $^{3}$; Ali Reza Pashaei ${ }^{4}$ \\ ${ }^{1}$ Department of Pathology, Faculty of Veterinary Medicine, Tehran University, Tehran, IR Iran \\ ${ }^{2}$ Department of Clinical Science, Science and Research Branch, Islamic Azad University, Tehran, IR Iran \\ ${ }^{3}$ Department of Clinical Science, Faculty of Veterinary Medicine, Tehran University, Tehran, IR Iran \\ 4 Private Veterinary Practitioner, Faculty of Veterinary Medicine, Tehran University, Tehran, IR Iran \\ ${ }^{*}$ Corresponding author: Farhang Sasani, Department of Pathology, Faculty of Veterinary Medicine, Tehran University, Tehran, IR Iran. Tel: +98-9121573490, Fax: +98-6693233222, E-mail: \\ fsasani@ut.ac.ir
}

Received: November 13, 2012; Revised: June 1, 2013; Accepted: October 23, 2013

\begin{abstract}
Background: The lesions induced by Helicobacter pylori in a candidate animal model should always be examined thoroughly. The resemblance of these lesions to those observed in humans can indicate whether the usage of this model will contribute to the understanding of the various pathogenic mechanisms involved in the development of human $H$. pylori-associated diseases.

Objectives: The aim of this study was to perform a histopathological and bacteriological evaluation of gastric lesions based on $H$. pylori and Helicobacter-like organisms (HLOs) in cats.

Materials and Methods: The present study was carried out on 28 cat's (13 male and 15 female cases) gastric mucosae, which were tested by bacteriological and histopathological methods. Biochemical tests such as catalase, oxidase and urease were utilized in addition to Gram and Giemsa staining.

Results: This research demonstrated that solely one case of H. pylori was isolated by gastric mucosal culture. Microscopically, the infected stomachs by HLOs comprised a mild to severe diffuse lymphoplasmacytic infiltration into the subglandular and gastric mucosa. Lymphoid follicles were also marked, particularly within pyloric tissues and mostly in displaced mucosal glands. For $75 \%$ of the gastritis cases, both HLOs and rapid urease tests were positive, whereas $83 \%$ of cases were more than one-year-old with gastritis. Furthermore, $75 \%$ of cats indicated gastritis, though $25 \%$ encompassed no gastritis; hence $20 \%$ had negative results for the rapid urease test and $25 \%$ for the Giemsa staining test. Such results may indicate that cats without gastritis were considered as free of HLOs pathogenic bacteria.

Conclusions: These results suggest that most cases of gastritis were located in the antral region. Additionally, the isolation of $H$. pylor from domestic cats raises the possibility of zoonotic characteristics for the slightly pathogen; therefore transmission occurs from cats to human and vice versa.
\end{abstract}

Keywords:Helicobacter pylori; Cat Diseases; Mucous Membrane

\section{Background}

Recent studies suggest a high prevalence of gastric Helicobacter infection in cats. Gastric Helicobacter-like organisms (HLO) have been observed in gastric biopsies of $41 \%$ to $100 \%$ of clinically healthy (1-3), and $57 \%$ to $100 \%$ of vomiting cats $(3,4)$. The development of animal models is important for the study of Helicobacter pylori pathogenesis. The need for suitable animals for this purpose has been clearly stated (5). To date, persistent colonization of the gastric mucosa and infection with $H$. pylori has been induced experimentally in gnotobiotic piglets, $(6,7)$ barrier-born pigs, $(7)$ nonhuman primates, $(8,9)$ gnotobiotic dogs, $(10)$ conventional dogs, (10) specific-pathogen-free (SPF) cats, (18 mice (SPF, germ-free, athymic, and transgenic), (11, 12) SPF Mon- golian gerbils, (13) rats, (14) and guinea pigs $(15,16)$

Spiral organisms have been described in the gastric mucosae of cats and dogs since the 19th century and are considered common inhabitants of the gastric mucosal niche (17). Three different morphological types were identified after ultrastructural analyses of the bacteria in situ; these types were originally presumed to represent various stages in the movement of one organism (18). Recent polyphasic taxonomy studies involving various isolates, however, revealed at least three different species belonging to the genus Helicobacter, namely, H. felis (13), $H$. bizzozeronii (6) and $H$. salomonis (11); these species are both phenotypically and phylogenetically highly related 
Sasani F et al.

\begin{tabular}{lccccc}
\multicolumn{1}{l}{ Table 1. Histopathological, Biochemical and Bacteriological Findings in Cats ${ }^{\text {a }}$} \\
\hline - & Gastritis & Rapid Urease Test & Geimsa Staining & Gram Staining & H.pylori Culture \\
\hline Positive & $21(75)$ & $20(80)$ & $18(75)$ & $16(94)$ & $1(5)$ \\
Negative & $7(25)$ & $5(20)$ & $6(25)$ & $1(6)$ & $20(95)$ \\
Total & $28(100)$ & $25(100)$ & $24(100)$ & $17(100)$ & $21(100)$ \\
\hline
\end{tabular}

${ }^{\mathrm{a}}$ Data are presented as No.(\%).

\begin{tabular}{lcccc}
\hline \multicolumn{1}{l}{ Table 2. Histopathological Finding of Gastric Tissues in Cats ${ }^{\text {a }}$} & & & \\
\hline- & Cardia & Body & Fundus & Antrum \\
\hline Positive gastritis & $15(60)$ & $16(70)$ & $19(70)$ & $18(78)$ \\
Negative gastritis & $10(40)$ & $7(30)$ & $8(30)$ & $5(22)$ \\
Total & $25(100)$ & $23(100)$ & $27(100)$ & $23(100)$ \\
\hline
\end{tabular}

a Data are presented as No.(\%).

(19). These tightly coiled organisms were largely ignored by the scientific community until the isolation of $H$.pylori from the human gastric mucosa renewed interest in gastric bacteria $(20,21)$.

\section{Objectives}

The purposes of this study were evaluation of histopathology of gastric mucosal changes and bacteriology studies of gastric bacteria, bacterial culture and identification of the isolated organisms on the basis of morphology, urease and catalase tests in cats. Finally, determination of whether naturally occurring gastric bacteria were associated with cats' gastritis.

\section{Materials and Methods}

\subsection{Animals, Preparation of Extracts, Isolation and Identification of Compounds}

Gastric tissues were collected during necropsy from 28 young and old stray cats (13 cases (46\%) were male and 15 (54\%) were females) and blood samples were taken in EDTA solution. Small pieces of gastric mucosa from body and antrum of the stomach were imprinted on glass slides, and were then stained by the Giemsa method. Furthermore, mucosal sections from the body and antrum were placed in tubes containing urea agar. Subsequently, the tubes were incubated at room temperature, monitored hourly for up to eight hours and then assessed. Development of a pink color in the gel was considered as a positive result. For the purpose of gastric organisms' isolation, small pieces of mucosal samples approximately $3 \times 3 \mathrm{~mm}$ from antrum, body, fundus, and cardia zones of the stomach were gathered for the bacterial culture. Every sample was placed in sterile Brucella broth (Rimmel) or Thiogluconate, for transport, abated in a sterile grinder, and then inoculated into the culture medium (Code no. BR56; Oxoid).
A Brucella agar base was supplemented with $10 \%$ horse blood and $5 \mathrm{mg} / \mathrm{L}$ trimethoprim, $10 \mathrm{mg} / \mathrm{L}$ vancomycin and $2500 \mu \mathrm{g}$ polymyxin-B for initial isolation of $H$. pylori (15). All culture plates were incubated for 5 to 7 days at 37$42^{\circ} \mathrm{C}$ in a moist microaerophilic atmosphere $\left(37^{\circ} \mathrm{C}, 10 \% \mathrm{C}_{2}\right.$, $5 \% \mathrm{O}_{2}, 85 \% \mathrm{~N}_{2}$ ). Furthermore, the cultured organisms were Gram stained in order to detect their staining adjectives and morphology. A loopful of culture was placed in two drops of urease reagent for the urease test, described previously (19). Standard methods were used for the catalase and oxidase tests. (Table 1).

\subsection{Histopathological Evaluation}

Every stomach was incised along the lesser curvature and the tissue samples were placed in $10 \%$ buffered formalin, and the sections of gastric tissues from the cardia, fundus, body and pyloric antrum of each cat were embedded in paraffin, prepared as 5 micron-thickness slices and stained with Hematoxylin and eosin and Giemsa methods (2.5\% in cacodylate buffer $(\mathrm{pH} 7)$ ). A gastric score was assigned to each section as follows: 0 (normal), 0 to 10 lymphocytes or plasma cells per 400 field; with no lymphoid aggregates and a normal gastric epithelium, 1 (mild gastritis); 10 to 50 lymphocytes or plasma cells per 400 field; with less than two follicles per 20 field and a normal epithelium, 2 (moderate gastritis); 10 to 50 or more lymphocytes or plasmacells per 400 field; with two or more follicles per 20 field and 3 (severe gastritis); 10 to 50 or more lymphocytes or plasmacells per 400 field and marked epithelium alterations. The frequency of lymphoid follicles present per 20 field was also noted. The histopathological findings for cats infected with Helicobacter spp. were compared with cats without HLOs pathogens. Cats were considered as infected with Helicobacter spp. while two or three tests (rapid urease test, Giemsa staining and culturing) were positive based on Neiger et al. (2) reports. 


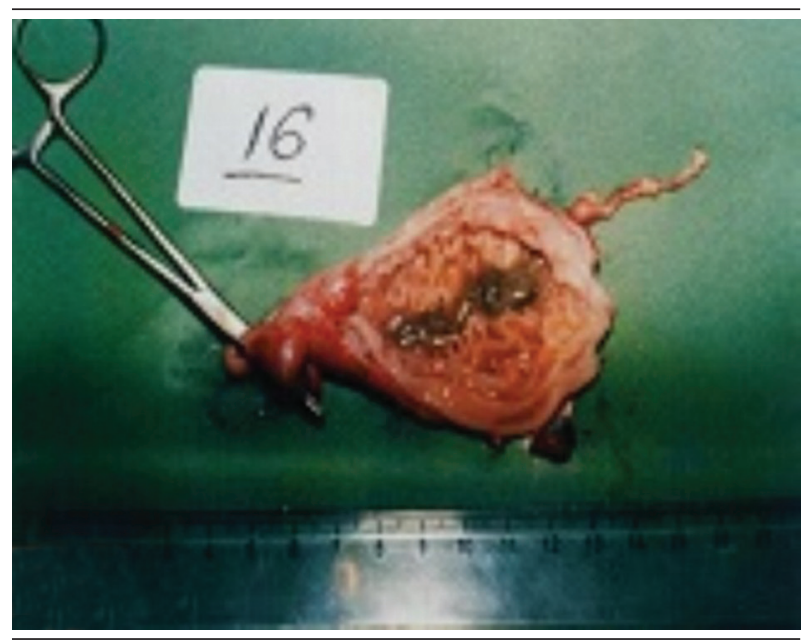

Figure 1. Lymphocytic Plasmacytic Gastritis in the Gastric Mucosa of a Cat With Naturally Acquired Helicobacter Species Infection Together with Chronic Follicular Gastritis (H\&E Stain)

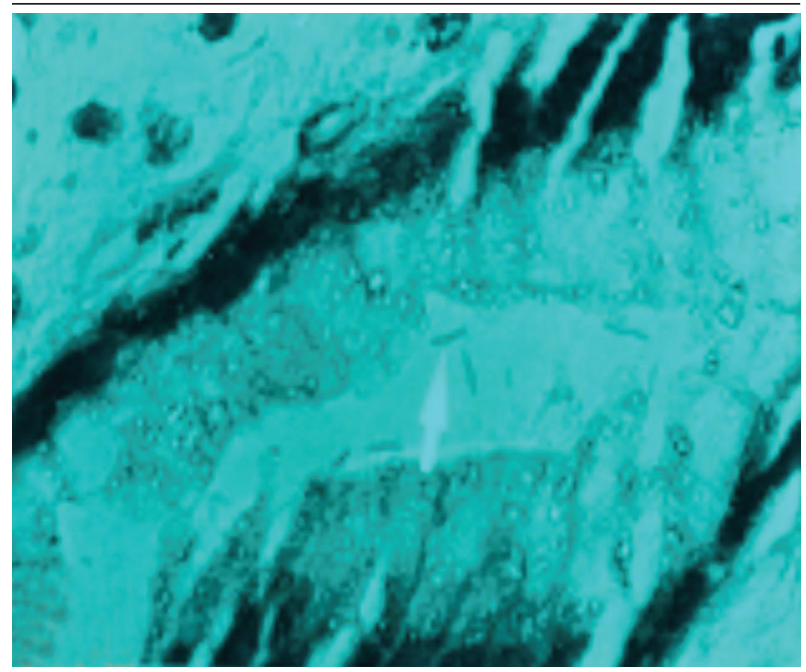

Figure 2. Arrows Indicate Helicobacter Species With a Spiral Shape and Dark Brown Colour in Cardia

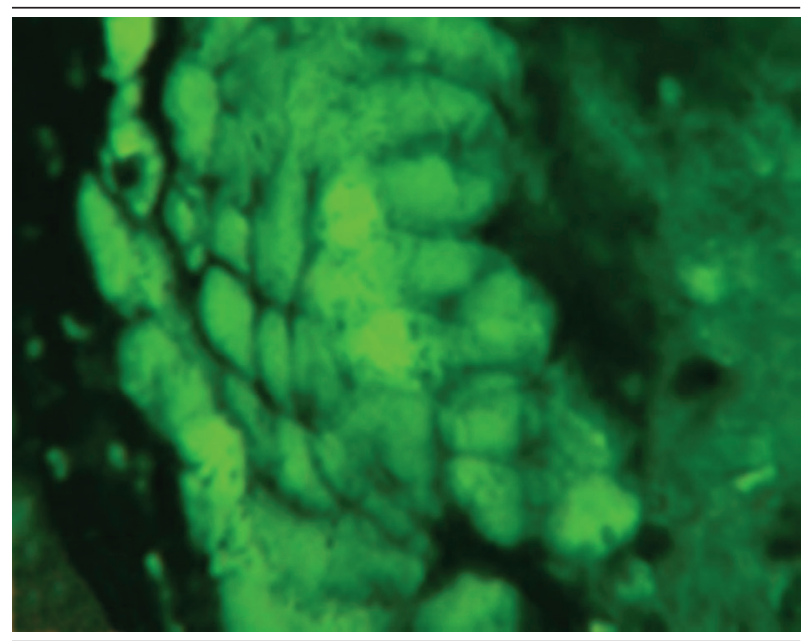

Figure 3. Photomicrograph Showing H. pylori in Gastric pit (Geimsa Staining, X1000, Grade)

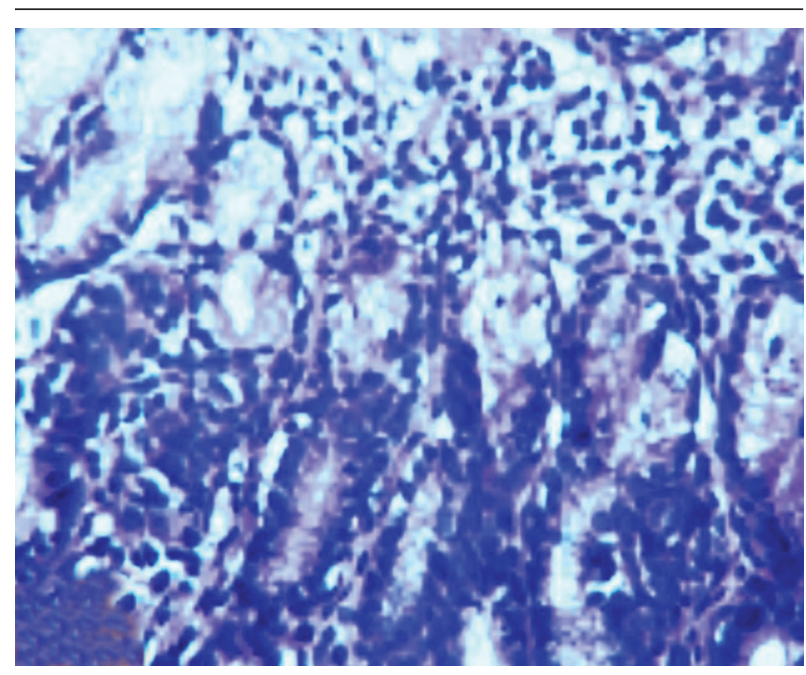

Figure 4. Lymphocytic Plasmacytic Gastritis in the Gastric Mucosa of a Cat with Naturally Acquired Helicobacter Species Infection Together with Chronic Follicular Gastritis (H\&E Stain)

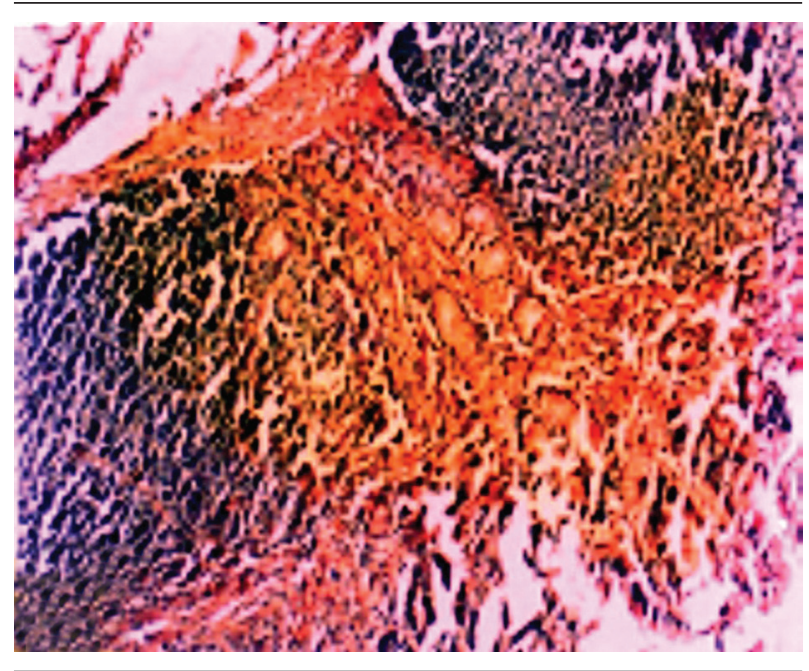

Figure 5. Mucosal Gastritis with Trichobezoar and Toxocara Cati

\section{Results}

In histopathological analysis of gastric tissues from cardia, fundus, body and antral regions of 28 cases, $75 \%$ of cats were affected by gastritis without clinical signs (Figure 1). The antral region was mostly affected (78\%) and the cardiac region (60\%) was the least affected region by gastritis (Table 2). Following impression smears, in 94\% of cases the cited bacteria were recorded by Gram staining. Concerning isolation of gastric spiral organisms, $H$. pylori was isolated from one cat but there were no possibilities for isolation of other HLOs spiral bacteria (Figure 2), (Figure 3), (Figure 4). Other bacteria such as pseudomonas aeroginosa, Bacillus cereus, Escherichia. coli, Enterococcus fecalis, Bacillus subtilis, Staphylococcus epidermis and Proteus mirabilis were isolated as well. Moreover, gastritis was observed (83\%) in more than one-year-old cats. Leukocy- 
tosis was detected in 30\% of cats with gastritis; however, $71 \%$ and $53 \%$ of cats developed neutrophilia and lymphopenia, respectively. Intestinal infestation of Toxacara cati (56\% of cats) was also determined (Figure 5).

\section{Discussion}

The aim of the present research was to record the frequency of spiral organisms of $H$. pylori and to determine the severity and location of gastritis in cats. Herman et al. (4) and Neiger et al. (2) indicated that $80 \%$ and $75 \%$ of cases had positive results for Helicobacter spp. through rapid urease test and Giemsa staining test, respectively. The results of the two studies represented that $78 \%$ of 32 cats and $76 \%$ of 127 cats possessed HLO infection $(4,22)$. By implementing histopathological techniques, Helicobacter spp. has been identified in $82 \%$ of cats; infected and uninfected cats either showed nil or moderate to severe signs of a gastritis. Furthermore, no correlation between inflammation and infection has been detectable as defined by Brandenburg et al. (23) who claimed that the prevalence of gastric $H$. pylori infection in dogs and cats was $85-100 \%$ and $H$. pylori might be pathogenic in cats, whereas these species have been merely found in colony and not in domestic cats (24).

In this study, $H$. pylori were isolated only from one cat from 20 tested stray cats. $H$. pylori appeared to be most prevalent in the antrum though in many animals plenty of such germs were detected in the fundus and body zones as reported by Handt et al. (25). Furthermore, Handt et al. explained that H.pylori presence in gastric tissue strongly supports the casual role of the bacterium in gastritis development (25). The multifocal lymphoplasmacytic infiltrate which often forms lymphoid follicles in $H$. pylori infected cats has been described for natural or experimental gastric Helicobacter infection in cats, dogs and ferrets as expressed by Handt et al. (25). There seems to be differences in the severity of gastritis in cats infected with diverse Helicobacter spp, as indicated by Neiger et al and Scanziani et al $(26,27)$.

In the present study, gastritis was observed in $75 \%$ of 28 cats while $25 \%$ of cases had no gastritis, so that $20 \%$ and $25 \%$ of them were negative in rapid urease test and Giemsa staining, respectively (Table 2 ). The obtained results may portend that cats without gastritis were free of Helicobacter spp. in their stomach. However, Hermanns et al. (4) reported that a relationship between the degree of colonization of HLOs and the extent of histopathological changes could be discovered in cats (28). In some studies (12-16), infection by H. pylori, H. felis and H. heilmannii, has been associated with a moderate to severe lymphofollicular gastritis in 21 ( $88 \%$ ) of 24 cats, and gastritis has markedly emerged in the antral region and consisted mainly of multifocal lymphoplasmacytic follicular infiltrates in deep mucosa due to chronic antigenic stimulation. In this study Helicobacter spp. have been abundant in fundus and most cases of gastritis were located in the an- tral region (78\%) as well as fundus (70\%), body (70\%) and cardia (60\%), which were involved with gastritis (Table 1). Due to the discovery of cats harboring $H$. pylori in a research colony (25) as well as in China (27) and according to preliminary data from France (29), cats may be a potential natural reservoir of $H$. pylori and could pose a zoonotic risk. In epidemiological studies, $H$. pylori-positive farm workers indicated greater contact with cats than with other animals (30). However, two studies evaluating H. pylori antibodies in cat owners and comparing them to humans without contact to cats revealed no increased risk in the first population $(31,32)$. A preliminary study on veterinarians had equally negative results for an increased risk of acquiring $H$.pylori infection from pets (22). Finally, isolation of $H$. pylori from stray and pet cats has not been possible for various studies $(33,34)$ suggesting that $H$. pylori infection in cats may be an anthroponosis, an animal infection with a human pathogen (9).

The discovery of $H$. pylori on the surface water has shifted the possibility of direct transmission from pets even further (25). Several reports on human patients have assumed a possible zoonotic transmission of large GHLO from dogs or cats (35-37). Only recently, an identical " $H$. heilmannii" organism identified by PCR and urease-B gene sequencing has been found in a patient and one of his cats (38). Several case reports on GHLOs infection in human have suggested animals as a possible source of infection $(17,23)$. One epidemiological study supported the hypothesis that cats should be considered as a source of zoonotic spread of GHLOs; however, data focused on $H$. felis and H. heilmannii, not H. pylori (9).

It seems that the stray cat can be used as an experimental model in future investigations of $H$. pylori-induced pathogenesis as well as evaluation of anti-H. pylori prevention and treatment regimens (39). The possible risk of transmission of large GHLO to human patients is rather small, considering the greater than $90 \%$ prevalence in dogs and cats and the rare (0.5\%) occurrence in humans. Notwithstanding, proper hygienic control is necessary to keep the risk at a minimum level.

\section{Acknowledgements}

The authors would like to thank the Department of Pathology, School of Veterinary Medicine, Tehran University and Parsa Veterinary Pathologic lab

\section{Authors' Contributions}

Farhang Sasani and FK participated in the histopathological evaluation, performed the literature review, acquired photomicrographs and drafted the manuscript and gave the final histopathological diagnosis. Javad javanbakht performed sequencing alignment and manuscript writing. Mehdi aghamohammad Hassan, Farrokh Reza|Kabir and Ali Reza Pashaei carried out the immunohistochemical stains evaluation and edited the manuscript and made required changes. All authors have read 
and approved the final manuscript.

\section{Financial Disclosure}

The authors report no conflicts of interest. The authors alone are responsible for the content and writing of the paper.

\section{Funding/Support}

This study was not funded.

\section{References}

1. De Majo M, Pennisi MG, Carbone M, Feres MT, Masucci M, Meli F. Occurrence of Helicobacter spp. in gastric biopsies of cats living in different kinds of colonies. Eur J Comp Gastroentero. 1998;13:1318.

2. Neiger R, Dieterich C, Burnens A, Waldvogel A, Corthesy-Theulaz I, Halter F, et al. Detection and prevalence of Helicobacter infection in pet cats. JClin Microbiol. 1998;36(3):634-7.

3. Yamasaki K, Suematsu H, Takahashi T. Comparison of gastric lesions in dogs and cats with and without gastric spiral organisms. J Am Vet Med Assoc. 1998;212(4):529-33.

4. Hermanns W, Kregel K, Breuer W, Lechner J. Helicobacter-like organisms: Histopathological examination of gastric biopsies from dogs and cats. J Comp Pathol. 1995;112(3):307-18.

5. Garcia JMP, Correa P, Perez GIP. Models of gastric Helicobacter infections. In: Pajares Garcia JM. editor. Helicobacter Pylori: Infection in Gastroduodenal Lesions.. Barcelona,Spain: Prous Science; 2000. p. 109-148.

6. Krakowka S, Morgan DR, Kraft WG, Leunk RD. Establishment of gastric Campylobacter pylori infection in the neonatal gnotobiotic piglet. Infect Immun. 1987;55(11):2789-96.

7. Lambert JR, Borromeo M, Pinkard KI, Turner H, Chapman CB Smith ML. Colonization of Gnotobiotic Piglets with Campylobacter pyloridis--An Animal Model? JInfect Dis. 1987;155(6):1344.

8. Dubois A, Berg DE, Incecik ET, Fiala N, Heman-Ackah LM, PerezPerez GI, et al. Transient and persistent experimental infection of nonhuman primates with Helicobacter pylori: implications for human disease. Infect Immun. 1996;64(8):2885-91.

9. Shuto R, Fujioka T, Kubota T, Nasu M. Experimental gastritis induced by Helicobacter pylori in Japanese monkeys. Infect Immun. 1993;61(3):933-9.

10. Binhazim AA, Chapman WJ, Shin SS, Hanson WL. Determination of virulence and pathogenesis of a canine strain of Leishmania leishmania infantum in hamsters and dogs. Am J Vet Res. 1993;54(1):113-21.

11. Richard LF, Jean-Michel T, Michel H, Agnes L. Immune Responses of Specific-Pathogen-Free cats to Chronic Helicobacter pylori (Strain SS1) Infection. Infect Immun. 1998;66(4):1349-55.

12. Guruge JL, Falk PG, Lorenz RG, Dans M, Wirth HP, Blaser MJ, et al Epithelial attachment alters the outcome of Helicobacter pylori infection. Proc Natl Acad Sci US A. 1998;95(7):3925-30.

13. Karita M, Kouchiyama T, Okita K, Nakazawa T. New small animal model for human gastric Helicobacter pylori infection: success in both nude and euthymic mice. Am J Gastroenterol. 1991;86(11):1596-603.

14. Karita M, Li Q, Cantero D, Okita K. Establishment of a small animal model for human Helicobacter pylori infection using germfree mouse. Am J Gastroenterol. 1994;89(2):208-13.

15. Lee A, O'Rourke J, De Ungria MC, Robertson B, Daskalopoulos G, Dixon MF. A standardized mouse model of Helicobacter pylori infection: Introducing the Sydney strain. Gastroenterology. 1997;112(4):1386-97.

16. Marchetti M, Arico B, Burroni D, Figura N, Rappuoli R, Ghiara P. Development of a mouse model of Helicobacter pylori infection that mimics human disease. Science. 1995;267(5204):1655-8.

17. Sturegard E, Sjunnesson H, Ho B, Willen R, Aleljung P, Ng HC, et al Severe gastritis in guinea-pigs infected with Helicobacter pylori. JMed Microbiol.1998;47(12):1123-9.
18. Happonen I, Saari S, Castren L, Tyni O, Hänninen ML, Westermarck E. Occurrence and Topographical Mapping of Gastric Helicobacter-like Organisms and Their Association with Histological Changes in Apparently Healthy Dogs and Cats. J Vet Med Series A. 1996;43(1-10):305-15.

19. Lockard VG, Boler RK. Ultrastructure of a spiraled microorganism in the gastric mucosa of dogs. Am J Vet Res. 1970;31(8):1453-62.

20. Jalava K, Kaartinen M, Utriainen M, Happonen I, Hanninen ML. Helicobacter salomonis sp. nov., a canine gastric Helicobacter sp. related to Helicobacter felis and Helicobacter bizzozeronii. Int $J$ Syst Bacteriol. 1997;47(4):975-82.

21. Marshall BJ, Warren JR. Unidentified Curved Bacilli in the Stomach of Patients with Gastritis and Peptic Ulceration. The Lancet. 1984;323(8390):1311-5.

22. Van den Bulck K, Decostere A, Baele M, Driessen A, Debongnie JC, Burette A, et al. Identification of non-Helicobacter pylori spiral organisms in gastric samples from humans, dogs, and cats. J Clin Microbiol. 2005;43(5):2256-60.

23. Brandenburg U, Pfeiffer I, Fabig G, Brenig B. Untersuchungen zum Vorkommen von Helicobacter spp. bei Hauskatzen . Kleintierpraxis. 2002;;47:205-12.

24. Hazell SL, Borody TJ, Gal A, Lee A. Campylobacter pyloridis gastritis I: Detection of urease as a marker of bacterial colonization and gastritis. Am J Gastroenterol. 1987;82(4):292-6.

25. Handt LK, Fox JG, Dewhirst FE, Fraser GJ, Paster BJ, Yan LL, et al Helicobacter pylori isolated from the domestic cat: public health implications. Infect Immun. 1994;62(6):2367-74.

26. Neiger R, Schmassmann A, Seidel KE. Antibododies against Helicobacter pylori and Helicobacter felis in veterinarians. Gastroenterol Int. 1998;11:127.

27. Scanziani E, Simpson KW, Monestiroli S, Soldati S, Strauss-Ayali D, Del Piero F. Histological and immunohistochemical detection of different Helicobacter species in the gastric mucosa of cats.J Vet Diagn Invest. 2001;13(1):3-12.

28. Engstrand L, Gustavsson S, Jorgensen A, Schwan A, Scheynius A. Inoculation of barrier-born pigs with Helicobacter pylori: a useful animal model for gastritis type B. Infect Immun. 1990;58(6):1763-8.

29. Zhou D, Yang H. Epidemiology of Helicobacter pylori infection in the People's Republic of China. Chin Med J(Engl).1995;108(4):30413.

30. Lecoindre P. About a case of Helicobacter pylori gastritis in a pet cat: Public health implications.Veldhoven, Belgium: ESVIM Forum; 1996.

31. Thomas DRh, Salmon RL, Meadows D, Morgan-Capner P, Kench SM, Coleman TJ. Incidence of Helicobacter pylori in Farmworkers and the Role of Zoonotic Spread. Gut. 1996:453-6.

32. Ansorg R, Heintschel Von Heinegg E, Von Recklinghausen G Cat Owners' Risk of Acquiring a Helicobacter pylori ilnfection. Zentralblatt für Bakteriologie. 1995;283(1):122-6.

33. Webb PM, Knight T, Elder JB, Newell DG, Forman D. Is Helicobacter pylori transmitted from cats to humans? Helicobacter. 1996;1(2):79-81.

34. Fox JG, Drolet R, Higgins R, Messier S, Yan L, Coleman BE, et al. Helicobacter canis isolated from a dog liver with multifocal necrotizing hepatitis. J Clin Microbiol. 1996;34(10):2479-82.

35. Wegmann W, Aschwanden M, Schaub N, Aenishanslin W, Gyr K. [Gastritis associated with Gastrospirillum hominis-a zoonosis?]. Schweiz Med Wochenschr.1991;121(8):245-54.

36. Meining A, Kroher G, Stolte M. Animal reservoirs in the transmission of Helicobacter heilmannii. Results of a questionnairebased study. Scand J Gastroenterol. 1998;33(8):795-8.

37. Dieterich C, Wiesel P, Neiger R, Blum A, Corthesy-Theulaz I. Presence of multiple "Helicobacter heilmannii" strains in an individual suffering from ulcers and in his two cats. J Clin Microbiol. 1998;36(5):1366-70.

38. Hanninen ML, Happonen I, Saari S, Jalava K. Culture and characteristics of Helicobacter bizzozeronii, a new canine gastric Helicobacter sp. Int J Syst Bacteriol. 1996;46(1):160-6.

39. Kkhoshnegah J, Jamshidi S, Mohammadi M, Shojaee Tabrizi A Mohajerani N, Zahraei Salehi T. Experimental infection of stray cats with human isolates of Helicobacter pylori. Iran J Vet Res. 2008;9(2):150-7. 